inverse association between appendicectomy, particularly at a young age, and later risk of ulcerative colitis. Importantly, however, such an association does not automatically imply a protective effect of childhood appendicectomy. One alternative explanation might be that the inverse association occurred, at least in part, because of underlying low rates of appendicitis in children destined to develop ulcerative colitis. In light of the marked and rather selective reduction in ulcerative colitis incidence among people who underwent appendicectomy for confirmed appendicitis before the age of 20 in the Swedish study, ${ }^{9}$ such an inverse association between childhood appendicitis, not appendicectomy, and risk of ulcerative colitis seems plausible. Another theoretical alternative is that appendicectomy rates might be low in people from families with a recognised predisposition to ulcerative colitis, if doctors are more hesitant to ascribe non-specific abdominal symptoms in these individuals to appendicitis. If these or similar mechanisms account for the repeatedly observed inverse association, appendicectomies would, at best, be irrelevant in attempts to prevent ulcerative colitis.

To better characterise the inverse association between appendicectomy and risk of ulcerative colitis, carefully designed and properly analysed large studies are required that enable a distinction between effects of appendicectomy and those associated with its most common underlying reason, appendicitis. Without substantive evidence to suggest a genuine protective effect of appendicectomy, any speculation about clinical trials to evaluate its therapeutic or preventive impact in relation to ulcerative colitis ${ }^{10-13}$ seems premature. Although appendicectomies are technically simple operations in most situations, complications can be serious and even life threatening. The health and hopes of patients with ulcerative colitis and their relatives are at stake-as is the reputation of the medical profession if premature action is taken on inconclusive evidence.

Morten Frisch senior researcher

(mfr@ssi.dk)

Division of Epidemiology, Department of Epidemiology Research, Statens Serum Institut, DK-2300 Copenhagen S, Denmark

Competing interests: None declared.

1 Gilat T, Hacohen D, Lilos P, Langman MJ. Childhood factors in ulcerative colitis and Crohn's disease. An international cooperative study. Scand J colitis and Crohn's disease. An in

2 Rutgeerts P, D'Haens G, Hiele M, Geboes K, Vantrappen G. Appendectomy protects against ulcerative colitis. Gastroenterology 1994;106:1251-3.

3 Frisch M, Johansen C, Mellemkjær L, Engels EA, Gridley G, Biggar RJ, et al. Appendectomy and subsequent risk of inflammatory bowel diseases. Surgery 2001;130:36-43.

4 Baron S, Turck D, Leplat C, Merle V, Gower-Rousseau C, Marti R, et al. Environmental risk factors in paediatric inflammatory bowel diseases: a population based case control study. Gut 2005;54:357-63.

5 Feeney MA, Murphy F, Clegg AJ, Trebble TM, Sharer NM, Snook JA. A case-control study of childhood environmental risk factors for the development of inflammatory bowel disease. Eur J Gastroenterol Hepatol opment of inflami
2002;14:529-34.

6 Gent AE, Hellier MD, Grace RH, Swarbrick ET, Coggon D. Inflammatory bowel disease and domestic hygiene in infancy. Lancet 1994;343:766-7.

7 Russel MG, Dorant E, Brummer RJ, van de Kruijs MA, Muris JW, Bergers $\mathrm{JM}$, et al. Appendectomy and the risk of developing ulcerative colitis or Crohn's disease: results of a large case-control study. South Limburg Inflammatory Bowel Disease Study Group. Gastroenterology 1997;113:377-82.

8 Uzan A, Jolly D, Berger E, Diebold MD, Geoffroy P, Renard P, et al. Effet protecteur de l'appendicectomie contre la rectocolite hémorragique. Etude cas-témoins [Protective effect of appendectomy on the development of ulcerative colitis. A case-control study]. Gastroenterol Clin Biol 2001:25:239-42.

9 Andersson RE, Olaison G, Tysk C, Ekbom A. Appendectomy and protection against ulcerative colitis. N Engl J Med 2001;344:808-14.

10 Hallas J, Gaist D, Sørensen HT. Appendectomy and ulcerative colitis (authors' reply). Epidemiology 2005;16:132-3.

11 Logan R. Appendectomy and ulcerative colitis: what connection? Gastroenterology 1994;106:1382-4.

12 Okazaki K, Onodera H, Watanabe N, Nakase H, Uose S, Matsushita M, et al. A patient with improvement of ulcerative colitis after appendectomy. Gastroenterology 2000;119:502-6.

13 Schattner A. Appendicectomy in ulcerative colitis. Lancet 1999;353:674.

\title{
Treating refractory epilepsy in adults
}

\section{The choice of drug or drug combinations is bewildering}

$\mathrm{M}$ ost adult patients with refractory epilepsy have partial (focal) seizures with or without secondary generalisation. During the 1970s and early 1980s studies showed that in $70-80 \%$ of adults with newly diagnosed epilepsy, seizures were controlled successfully by carefully monitored monotherapy with any of the four standard antiepileptic drugsphenobarbital, phenytoin, carbamazepine, or sodium valproate-all of which seemed to have similar efficacy in partial epilepsy in later comparative trials of monotherapy. ${ }^{1-4}$ Furthermore, adding a second drug for patients with continuing seizures on optimum monotherapy led to modest benefit in no more than one third, a deterioration in seizure control or unacceptable toxicity in about a quarter, and no change in the rest. ${ }^{25}$

These studies led to important questions. Should patients unresponsive to the optimum use of the first drug be switched to alternative monotherapy or treated with polytherapy? If so, which drug or drug combination is appropriate?

Twenty years later these questions remain unanswered. Meanwhile 10 new drugs have been licensed and marketed in the United Kingdom as adjunctive therapy in adults for resistant mainly partial epilepsies: clobazam, vigabatrin, lamotrigine, gabapentin, topiramate, tiagabine, levetiracetam, oxcarbazepine, pregabalin, and zonisamide.

The only pragmatic controlled clinical trial of adjunctive therapy in partial epilepsy that was unresponsive to a single drug showed that the probability of remaining free of seizures over the next year was $16 \%$ for patients on adjunctive therapy and $14 \%$ for those switched to alternative monotherapy. ${ }^{6}$ The authors emphasised that the trial was statistically underpowered and that they had had difficulty in recruitment because of financial competition from commercial sponsors targeting similar patients for new drug trials. In a prospective observational study of 422 newly diagnosed patients, $47 \%$ became seizure free on the first drug and only an additional $14 \%$ on alternative monotherapy with a second or third drug, whereas only $3 \%$ were seizure free on a combination of two drugs-all of which implies a need to consider surgery in appropriately selected patients earlier. ${ }^{7}$ 
Interestingly, freedom from seizures was almost identical, whether patients were treated first with a standard drug or a new drug.

The recent guidelines from the National Institute for Health and Clinical Excellence (NICE) on newer drugs for epilepsy in adults is therefore vague on the management of refractory epilepsy because of a lack of data comparing the new drugs with each other or with standard drugs, either as monotherapy or combination therapy. ${ }^{8}$ NICE recommends that combination therapy should be considered only when attempts at monotherapy have not resulted in freedom from seizures but gives no guidance on the number of attempts at monotherapy or which combination to try. I estimate that the bewildered general neurologist or physician can choose from up to 13 options for monotherapy and 91 options for combination therapy. This is clearly an unsatisfactory situation for patients and physicians alike.

Doctors tend to opt for their own favourite combinations, influenced by marketing pressures or based on speculative concepts of different mechanisms of drug action or synergy-concepts that originally led to the subsequently discredited combined capsules of phenobarbital and phenytoin. ${ }^{9}$ Switching to alternative monotherapy is more time consuming and requires careful clinical monitoring. It is easier to add a second drug, and if there is some clinical improvement, as occurs in up to one third of patients, it is tempting but possibly erroneous to assume that improvement is due to the combination rather than to the second drug. Such thinking perpetuates the phenomenon and scale of polytherapy. ${ }^{2}$ Furthermore, combination therapy increases the risk of side effects, including teratogenicity, ${ }^{10}$ especially if the drugs are similar (for example, carbamazepine and oxcarbazepine) or if they interact (for example, lamotrigine and valproate or carbamazepine).

In treating epilepsy in childhood, similar problems arise. Compared with adults, however, children have a much higher incidence of idiopathic generalised epilepsy syndromes, for which some standard or new drugs, such as carbamazepine or vigabatrin, may be inappropriate. In addition, fewer of the new drugs have been licensed for use in children, and comparative data on different drug treatments are even scarcer. ${ }^{11}$

The pharmaceutical industry finances $90 \%$ of all clinical trials in the UK. ${ }^{12}$ But industry has no interest in supporting large scale, long term pragmatic trials that might provide evidence to reduce much unnecessary polytherapy and therefore restrict the market for many of the newer drugs. Academics specialising in epilepsy will therefore have to clarify, through research, how much real progress has been made in managing resistant epilepsy since the era of phenobarbital and phenytoin.

Edward Reynolds honorary senior lecturer

(reynolds@buckles.u-net.com)

Institute of Epileptology, King's College, London SE5 6PJ

Competing interests: None declared.

Reynolds EH, Chadwick D, Galbraith AW. One drug (phenytoin) in the treatment of epilepsy. Lancet 1976;1:923-6.

2 Reynolds EH, Shorvon SD. Monotherapy or polytherapy for epilepsy? Epilepsia 1981;22:1-10.

3 Mattson RH, Cramer JA, Collins JF, Smith DB, Delgado-Escueta AV, Browne TR, et al. Comparison of carbamazepine, phenobarbital, phenytoin and primidone in partial and secondarily generalised tonic-clonic seizures. N Engl J Med 1985;313:145-51.

4 Heller AJ, Chesterman P, Elwes RDC, Crawford P, Chadwick D, Johnson AL, et al. Phenobarbitone, phenytoin, carbamazepine or sodium valproate for newly diagnosed adult epilepsy: a randomised comparative monotherapy trial. J Neurol Neurosurg Psychiatry 1995;58:44-50.

5 Schmidt D. Two anti-epileptic drugs for intractable epilepsy with Schmidt D. Two anti-epileptic drugs for intractable epilepsy with
complex-partial seizures. I Neurol Neurosurg Psychiatry 1982;45: 1119-24.

6 Beghi E, Gatti G, Tonini C, Ben-Menachem E, Chadwick DW, Nikanorova $\mathrm{M}$, et al. Adjunctive therapy versus alternative monotherapy in patients with partial epilepsy failing on a single drug: a multi-centre, randomised, pragmatic controlled trial. Epilepsy Res 2003;57:1-13.

7 Kwan P, Brodie MJ. Early identification of refractory epilepsy. $N$ Engl J Med 2000;342:314-9.

National Institute for Clinical Excellence. Newer drugs for epilepsy in adults. NICE Technology Appraisal Guidance 76. London: NICE, 2004.

9 Macdonald RL. Is there a mechanistic basis for rational polypharmacy? Epilepsy Res 1996;11:79-93.

10 Morrow JI, Russell A, Gutherie E, Parsons L, Robertson I, Waddell R, et al Malformation risks of anti-epileptic drugs in pregnancy: a prospective study from the UK epilepsy and pregnancy register. J Neurol Neurosurg study from the UK epilepsy and pregnancy register. J Neurol Neurosurg
Psychiatry 2005. Published online 12 Sep 2005. doi: 10.1136 . jnnp.2005.074203.

11 De Silva M, MacArdle B, McGowan M, Hughes E, Stewart J, Neville BGR, et al. Randomised comparative monotherapy trial of phenobarbitone, phenytoin, carbamazepine, or sodium valproate for newly diagnosed childhood epilepsy. Lancet 1996;347:709-13.

12 Ferner RE. The influence of big pharma. BMJ 2005;330:855-6.

\title{
The burden of chronic kidney disease
}

\author{
Is rising rapidly worldwide
}

$\mathrm{T}$ he number of patients with chronic kidney disease worldwide is rising markedly. ${ }^{1}$ In the United Kingdom, the annual incidence of end stage renal disease is around 100 per 1000000 population. ${ }^{2}$ This incidence has doubled over the past decade and is expected to continue to rise by $5-8 \%$ annually, but it remains well below the European average (around 135/1000 000) and that of the United States $(336 / 1000000){ }^{3}$

Disparities in the incidence of end stage renal disease within and between developed countries reflect racial and ethnic diversity. In the US, the annual incidence is 256/1000 000 in white people compared with 982/1 000000 in African-Americans. ${ }^{3}$ In Australia, the incidence in white people is comparable to that in the UK (94/1 000000$)$, but the incidence in aboriginals is $420 / 1000000$.

The rise in end stage renal disease worldwide most probably reflects the global epidemic of type 2 diabetes and the ageing of the populations in developed countries, with a higher incidence in elderly people (the annual incidence in people over 65 in the UK is greater than $350 / 1000000,{ }^{2}$ and in the US it is greater than $1200 / 1000000){ }^{3}$. The number of people with diabetes worldwide, currently around 154 million, is set to double within the next 20 years, and the increase will be 